David G. Casey, ${ }^{1}$ Ph.D.; Katarina Domijan, ${ }^{2}$ Ph.D.; Sarah MacNeill, ${ }^{1}$ B.Sc.; Damien Rizet, ${ }^{1}$ M.Sc.; Declan O'Connell, ${ }^{1}$ B.Sc.; and Jennifer Ryan, ${ }^{1}$ Ph.D.

\title{
The Persistence of Sperm and the Development of Time Since Intercourse (TSI) Guidelines in Sexual Assault Cases at Forensic Science Ireland, Dublin, Ireland
}

\begin{abstract}
The persistence of sperm using confirmatory microscopic analysis, the persistence of sperm with tails, time since intercourse (TSI) analysis, and results from the acid phosphatase (AP) reaction from approximately 5581 swabs taken from circa 1450 sexual assault cases are presented. The observed proportions of sperm in the vagina and anus declines significantly after $48 \mathrm{~h}$ TSI, and sperm on oral swabs were observed up to $15 \mathrm{~h}$ TSI. The AP reaction as a predictor of sperm on intimate swabs is questioned. All AP reaction times gave a low true positive rate; $23 \%$ of sperm-positive swabs gave a negative AP reaction time. We show the AP reaction is an unsafe and an unreliable predictor of sperm on intimate swabs. We propose that TSI not AP informs precase assessment and the evaluative approach for sexual assault cases. To help inform an evaluative approach, TSI guidelines are presented.
\end{abstract}

KEYWORDS: forensic science, sexual assaults, persistence of sperm, time since intercourse, acid phosphatase, expert evaluative opinion

The forensic investigation into sexual assault cases primarily focuses on the presence or absence of sperm. As the primary body fluid of interest, a knowledge of the persistence of sperm in the mouth, anus, and vagina of victims can assist in the assessment and interpretation of these case types and can assist the forensic scientist when explaining the significance of the sperm results in a court of law. This knowledge is invaluable especially in cases that require an evaluative approach. Sperm are the most unequivocal and the longest surviving seminal constituent (1). As such, the presence of sperm is the confirmatory tool of choice for the presence of sperm. The most pertinent publications (2-10) detailing the persistence of sperm on intimate swabs have predominantly been based on small numbers of case studies or from volunteer donors rather than the large population data set of actual cases as presented in this study. There is a particular shortage of published information on the persistence of sperm following anal and oral intercourse, the persistence of sperm with intact tails, acid phosphatase (AP) as an indicator of sperm, and the development of evidence-based time since intercourse (TSI) opinions. Allard (3) in 1997 stated "analysis of the data for the most likely time (since intercourse) awaits statistical analysis." We present here statistical analysis of the persistence of sperm, associated acid phosphatase reaction times, and an

\footnotetext{
${ }^{1}$ Department of Justice and Equality, Forensic Science Ireland, Garda Headquarters, Phoenix Park, Dublin 8, Ireland.

${ }^{2}$ Department of Mathematics and Statistics, Maynooth University, Co. Kildare, Ireland.

Received 26 Oct. 2015; and in revised form 28 April 2016; accepted 7 Aug. 2016.
}

interpretation of TSI data. Our analysis supports an evidencebased TSI approach to the investigation and evaluation of sexual assault cases.

To inform an evidence-based TSI approach to sexual assaults, we set out to address a number of frequently asked questions raised by the forensic scientist when investigating sexual assault cases:

- Is there a time interval that you would have an expectation of finding sperm on vaginal swabs?

- Is there a time interval that you would have an expectation of finding sperm with tails on vaginal swabs?

- Is there a time interval that you would have an expectation of finding sperm on internal anal swabs?

- Is there a time interval that you would have an expectation of finding sperm on internal oral swabs?

- Is AP time a good indicator for the presence of sperm on vaginal swabs?

- What, if any, is the best cutoff time for the AP reaction on swabs?

- Is there a relationship between AP reaction time and the TSI in our data set?

- Is there a relationship between AP reaction time and TSI when vaginal swabs are positive or negative?

In total 1450 cases were examined between 2000 and 2007 at Forensic Science Ireland (FSI) which contained approximately 5581 swabs* - 3508 vaginal swabs, 1224 anal swabs, of which

*Some of these swabs were without TSI information and AP information and were not included in some analyses 
538 were internal anal swabs, and 849 oral swabs of which 464 were internal oral swabs. External mouth and anal swabs and swabs from other external bodily areas were not examined in this study. Data from deceased victims is not included in the sexual assault database (SAD).

\section{Methods}

Sperm presence/absence was confirmed by microscopic examination. Briefly intimate swabs were sampled by cutting away a small piece of the swab tip, macerating in $\mathrm{ddH}_{2} \mathrm{O}$ on a slide. The cut piece is removed for AP testing using the Brentamine test (Brentamine Fast Blue B), and the remaining slide debris is heatdried and fixed followed by standard H\&E staining as described by Clarke (1) and Kind (2). Microscopic confirmation and abundance of sperm was classified as described by Allard (3), 4+ (many in every field), $3+$ (many or some in most fields), $2+$ (some in some fields easy to find, $1+$ (hard to find), and trace (1 unequivocal sperm head/3 or more sperm heads following independent agreement) (T) indicates the presence of tails on spermatozoa.

Swabs are categorized in the sexual assault database (SAD) into the following groups:

- Vaginal swabs,

(a) Endocervical or cervical

(b) HVS (swabs labeled "high or upper vaginal")

(c) LVS (swabs labeled "low or mid vaginal")

(d) EVS (swabs labeled "external vaginal swabs; vulva, forchette, labial major, labial minor, mons pubis" and including any external vaginal locations).

- Anal swabs,

(a) IAS (swabs labeled "internal or rectal")

- Oral swabs,

(a) IMS (swabs labeled "internal mouth, cheek, teeth, gums")

\section{Data Collection and Analysis}

The information used in this study is based on the case file information provided to Forensic Science Ireland (FSI) by the forensic medical examiners forms, the submission forms from the Irish Police (An Garda Síochána) and the laboratories' scientific results as described by Lee-Gorman et al. (4). The case information is recorded in the case file, and the scientific findings are recorded in the SAD. The SAD captures all the information related to body fluid testing and the findings included are swab label, sperm grading, AP time, presence of tails and results from the RSID semen, and saliva kits for the detection of seminal fluid and human salivary amylase $(5,6)$. The information in the SAD and its statistical analysis were not subjected to any preselection in relation to the case circumstances, including the age or recollection of the complainant or any previous sexual activity. Sperm results for each type of swab (endocervical, HVS, LVS, EVS, IMS, and IAS) and the AP reaction times from each swab group were categorized into what the authors consider forensically informative TSI intervals and AP reaction times. In the presented tables and figures, a 120-sec time (a negative AP finding) is denoted as AP time $\geq 120 \mathrm{sec}$. Statistical analysis (chi-square goodness-of-fit tests) was performed in Minitab $^{\circledR}$ 17.1.0. Information taken from casework can run the risk of having incorrect details supplied at the time of submission and transcription errors when being entered into the SAD. Therefore, information in the SAD was validated by randomly choosing 100 case files and a manual conformation of the provided information and scientific findings carried out against the case file information.

\section{Discussion}

Question 1

Is there a time interval that you would have an expectation of finding sperm on vaginal swabs?

The compiled results for all sperm-positive vaginal swabs up to a TSI of $72 \mathrm{~h}$ are presented in Table 1. The difference between the proportions of sperm-positive vaginal swabs at different time intervals is statistically significant ( $p$-value $<0.001)$. The expected proportion of sperm-positive vaginal swabs at TSI intervals with a $95 \%$ confidence interval (CI) is shown in Fig. 1. This analysis shows that as a guideline, the expectation of observing sperm in the vagina decreases significantly after $18 \mathrm{~h}$ (0.35) and again after $48 \mathrm{~h}(0.2)$, and beyond $96 \mathrm{~h}$, the expectation of observing sperm in the vagina can be considered extremely low (0.02) (Fig. 1, Table 2).

The persistence times for each individual vaginal swab type are presented in Figs 2-5. Included for reference are data tables for each swab type (Tables 3-6). In terms of sperm distribution, trace and $1+$ were the most common grade recorded beyond $48 \mathrm{~h}$ (Figs 2-5). The longest recorded persistence time for sperm in the SAD was a $1+$ on a HVS sampled at a TSI of approximately $96 \mathrm{~h}$ after alleged intercourse (Fig. 3). No sperm was recorded on any vaginal swab type beyond $96 \mathrm{~h}$.

\section{Question 2}

Is there a time interval that you would have an expectation of finding sperm with tails on vaginal swabs?

TABLE 1-The percentage of all sperm-positive vaginal swabs up to $72 h$.

\begin{tabular}{lrrrr}
\hline TSI (h) & $0-24$ & $24-48$ & $48-72$ & Total swabs \\
\hline Positive & 889 & 113 & 13 & 1015 \\
Negative & 1734 & 294 & 195 & 2223 \\
Total & 2623 & 407 & 208 & 3238 \\
\% Positive & 34 & 28 & 6 & 31 \\
\hline
\end{tabular}

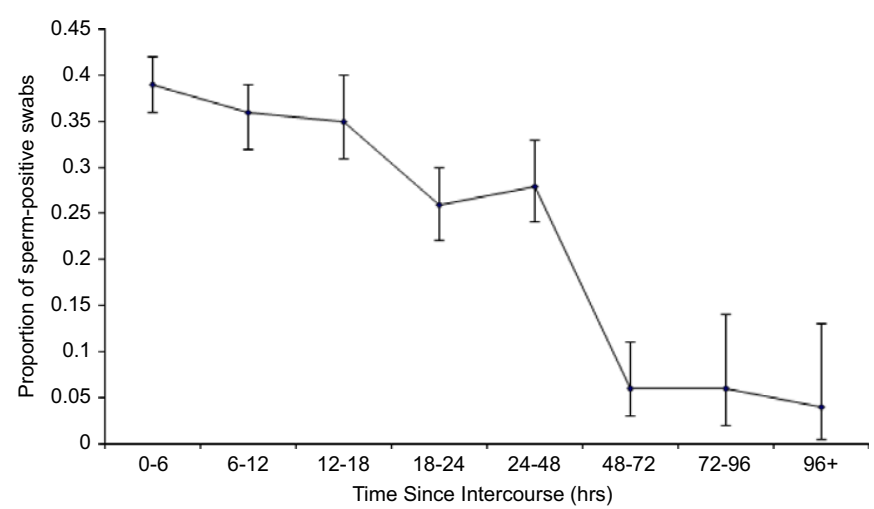

FIG. 1-Proportion of sperm-positive vaginal swabs with 95\% C.I. within each time interval [Color figure can be viewed at wileyonlinelibrary.com] 
TABLE 2-The proportion of sperm-positive vaginal swabs at different intervals with $95 \%$ CI.

\begin{tabular}{lcccc}
\hline TSI $(\mathrm{h})$ & $\begin{array}{c}\text { No. of positive } \\
\text { swabs }\end{array}$ & $\begin{array}{c}\text { Total no. } \\
\text { of swabs }\end{array}$ & $\begin{array}{c}\text { Proportion of } \\
\text { positive swabs }\end{array}$ & $\begin{array}{c}95 \% \text { confidence } \\
\text { interval }\end{array}$ \\
\hline $0-6$ & 367 & 943 & 0.39 & $(0.36,0.42)$ \\
$06-12$ & 265 & 746 & 0.36 & $(0.32,0.39)$ \\
$12-18$ & 162 & 464 & 0.35 & $(0.31,0.40)$ \\
$18-24$ & 127 & 493 & 0.26 & $(0.22,0.30)$ \\
$24-48$ & 116 & 410 & 0.28 & $(0.24,0.33)$ \\
$48-72$ & 13 & 208 & 0.06 & $(0.03,0.11)$ \\
$72-96$ & 5 & 79 & 0.06 & $(0.02,0.14)$ \\
$96+$ & 1 & 52 & 0.02 & $(0.002,0.15)$ \\
\hline
\end{tabular}

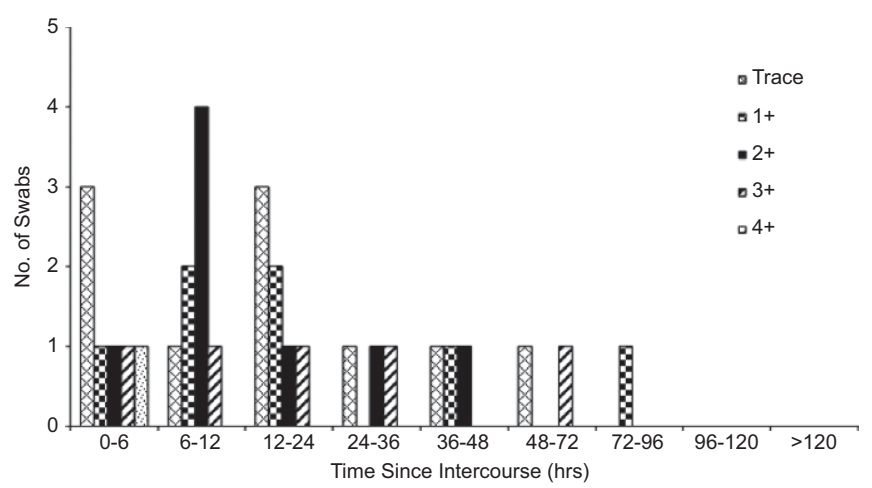

FIG. 2-Persistence and grading of sperm on endocervical swabs at each TSI. Total number of swabs: 103

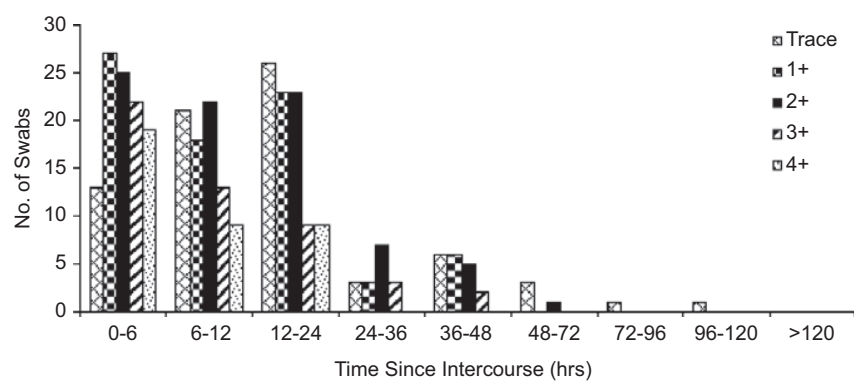

FIG. 3-Persistence and grading of sperm on high vaginal swabs (HVS) at each TSI. Total number of swabs: 1061

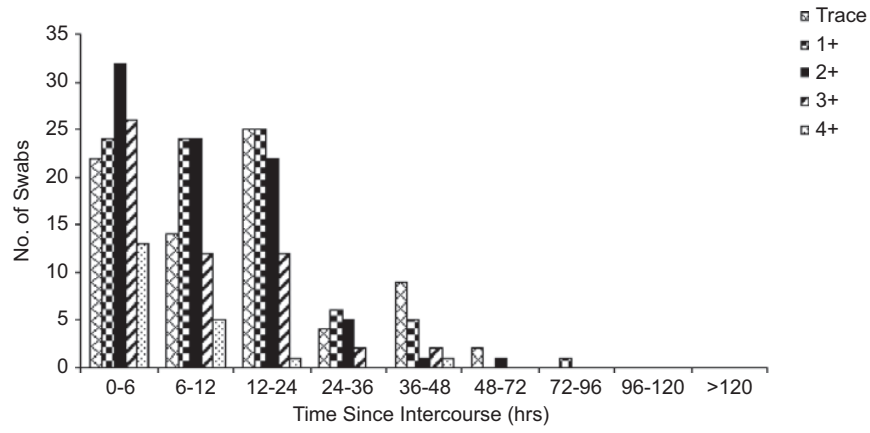

FIG. 4-Persistence and grading of sperm on low vaginal swabs (LVS) at each TSI. Total number of swabs: 1092

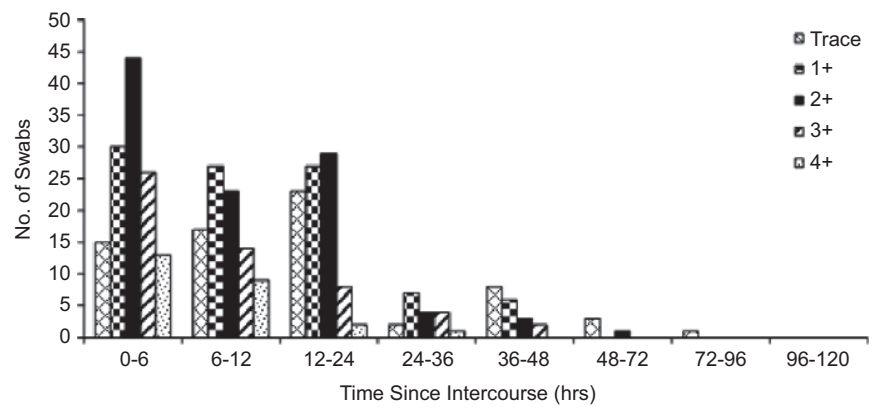

FIG. 5-Persistence and grading of sperm on external vaginal swabs (EVS) at each TSI. Total number of swabs: 1111

TABLE 3-The percentage of sperm-positive endocervical swabs at each TSI.

\begin{tabular}{lrrrrrrrrr}
\hline TSI & $0-$ & $6-$ & $12-$ & $24-$ & $36-$ & $48-$ & $72-$ & $96-$ & Total \\
(h) & 6 & 12 & 24 & 36 & 48 & 72 & 96 & 120 & swabs \\
\hline Positive & 7 & 8 & 7 & 3 & 3 & 2 & 1 & 0 & 31 \\
Negative & 11 & 15 & 18 & 3 & 4 & 15 & 4 & 2 & 72 \\
Total & 18 & 23 & 25 & 6 & 7 & 17 & 5 & 2 & 103 \\
\% Positive & 39 & 35 & 28 & 50 & 43 & 12 & 20 & 0 & 30 \\
\hline
\end{tabular}

TABLE 4-The percentage of sperm-positive high vaginal swabs at each TSI.

\begin{tabular}{lrrrrrrrrrr}
\hline & $0-$ & $6-$ & $12-$ & $24-$ & $36-$ & $48-$ & $72-$ & $96-$ & & Total \\
TSI (h) & 6 & 12 & 24 & 36 & 48 & 72 & 96 & 120 & $>120$ & swabs \\
\hline Positive & 106 & 83 & 90 & 16 & 19 & 4 & 1 & 1 & 0 & 320 \\
Negative & 190 & 152 & 206 & 44 & 44 & 58 & 20 & 19 & 8 & 741 \\
Total & 296 & 235 & 296 & 60 & 63 & 62 & 21 & 20 & 8 & 1061 \\
\% Positive & 36 & 35 & 30 & 27 & 30 & 6 & 5 & 5 & 0 & 30 \\
\hline
\end{tabular}

TABLE 5-The percentage of sperm-positive low vaginal swabs at each TSI.

\begin{tabular}{lrrrrrrrrrr}
\hline & $0-$ & $6-$ & $12-$ & $24-$ & $36-$ & $48-$ & $72-$ & $96-$ & $>$ & Total \\
TSI (h) & 6 & 12 & 24 & 36 & 48 & 72 & 96 & 120 & 120 & swabs \\
\hline Positive & 117 & 79 & 85 & 17 & 18 & 3 & 1 & 0 & 0 & 321 \\
Negative & 192 & 166 & 219 & 45 & 51 & 61 & 23 & 9 & 5 & 771 \\
Total & 309 & 245 & 304 & 62 & 69 & 64 & 24 & 9 & 5 & 1092 \\
\% Positive & 38 & 32 & 28 & 27 & 26 & 5 & 4 & 0 & 0 & 29 \\
\hline
\end{tabular}

TABLE 6-The percentage of sperm-positive external vaginal swabs at each TSI.

\begin{tabular}{lrrrrrrrrr}
\hline & $0-$ & $6-$ & $12-$ & $24-$ & $36-$ & $48-$ & $72-$ & $96-$ & Total \\
TSI (h) & 6 & 12 & 24 & 36 & 48 & 72 & 96 & 120 & swabs \\
\hline Positive & 128 & 90 & 89 & 18 & 19 & 4 & 1 & 0 & 349 \\
Negative & 181 & 154 & 230 & 51 & 52 & 61 & 24 & 9 & 762 \\
Total & 309 & 244 & 319 & 69 & 71 & 65 & 25 & 9 & 1111 \\
\% Positive & 41 & 37 & 78 & 29 & 28 & 6 & 4 & 0 & 31 \\
\hline
\end{tabular}

The morphological characteristics (shape, coloration, and definition) of sperm degrade over time in the vagina. Qualitative changes due to TSI usually result in the loss of tails, the loss of quality, and a reduction in sperm abundance. The presence of tails can be useful for TSI estimations, but the time lapse associated with the loss of tails is unclear (7). Silvermann (8) found no significant difference in the proportion of sperm with or 


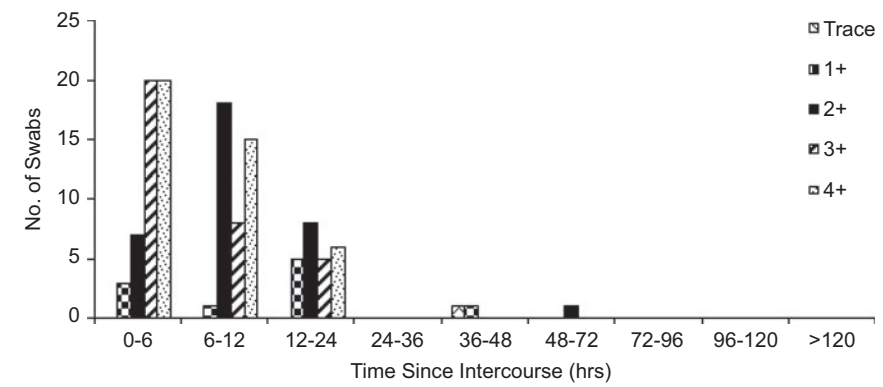

FIG. 6-Persistence and grading of sperm with tails on internal vaginal swabs at each TSI. Total number of swabs: 932

without tails at any time after sexual intercourse and has suggested that the loss of tails is not a useful indicator of time since intercourse. Our findings show that this is not the case; within the first $12 \mathrm{~h}$, the expectation of observing sperm-positive vaginal swabs tails was 0.15 , and this expectation declines at a TSI greater than $24 \mathrm{~h}(0.09)$ (Fig. 6). This would be in agreement with the study by ADavies (9), where tails were most frequently found on sperm swabs taken up to $12 \mathrm{~h}$. However, sperm with tails have been reported as late as $72 \mathrm{~h}(10)$. No oral or anal sperm-positive swabs with tails were recorded in the database. Our findings show that the expectation of finding sperm with tails after $24 \mathrm{~h}$ is very low (Table 7) and that sperm with tails on vaginal swabs are more likely to be detected within $12 \mathrm{~h}$ TSI.

\section{Question 3}

Is there a time interval that you would have an expectation of finding sperm on internal anal swabs?

There is little published information on the persistence of sperm in the anus. In general, sperm can be detected in the anus up to $24 \mathrm{~h}$ TSI. Sperm can persist for over 2 days after anal

TABLE 7-The percentage of sperm with tails at each time TSI (vaginal swabs only).

\begin{tabular}{lrrrrrrr}
\hline TSI (h) & $0-6$ & $6-12$ & $12-24$ & $24-36$ & $36-48$ & $48-72$ & $72-96$ \\
\hline Positive & 358 & 260 & 271 & 54 & 59 & 13 & 4 \\
With tails & 50 & 42 & 24 & 0 & 2 & 1 & 0 \\
Total & 932 & 747 & 944 & 197 & 210 & 208 & 75 \\
\% Positive with tails & 14 & 16 & 9 & 0.0 & 4 & 0.08 & 0.0 \\
\hline
\end{tabular}

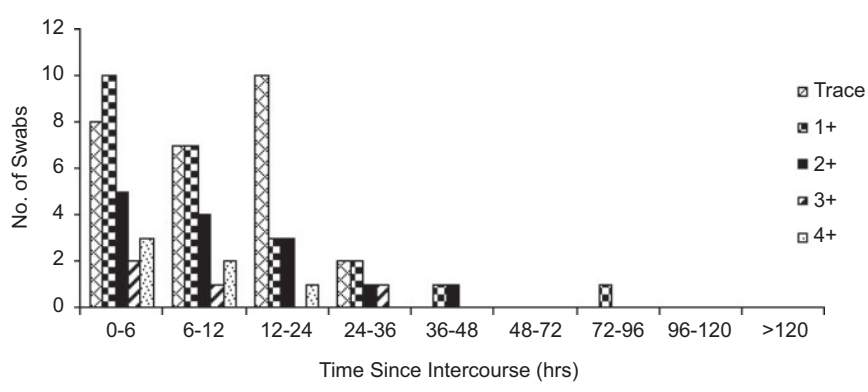

FIG. 7-Persistence and grading of sperm on internal anal swabs (IAS) at each TSI. Total number of swabs: 510
TABLE 8-The percentage of sperm-positive internal anal swabs at each TSI.

\begin{tabular}{lrccccc}
\hline TSI (hrs) & $0-24$ & $24-48$ & $48-72$ & $72-96$ & $96-120$ & Total swabs \\
\hline Positive & 65 & 8 & 0 & 1 & 0 & 74 \\
Negative & 335 & 61 & 27 & 8 & 5 & 436 \\
Total & 400 & 69 & 27 & 9 & 5 & 510 \\
\% Positive & 16 & 12 & 0 & 11 & 0 & 15 \\
\hline
\end{tabular}

An additional 27 IAS were taken, four of which were positive, but no TSI was provided for these.

intercourse (9). A total of 510 internal anal swabs were examined in this study. The persistence and distribution of spermpositive anal swabs at each TSI shown are Fig. 7 and Table 8. The expectation of observing a sperm-positive anal swab at a TSI of less than $6 \mathrm{~h}$ is 0.24 , and this expectation drops as the TSI increases. The expectation of finding anal swabs positive for sperm at a TSI of less than $48 \mathrm{~h}(0.16)$ can be considered low, and the expectation of finding sperm at TSI greater than $48 \mathrm{~h}$ can be considered extremely low, 0.023 (Table 9), as it was observed only once of 42 swabs at a TSI greater than $48 \mathrm{~h}$. Our experience at FSI is that it is unlikely that sperm will be detected on internal swabs beyond a TSI of $24 \mathrm{~h}$. Generally, the examination for the presence of sperm in internal anal swabs is not carried out beyond a TSI of $72 \mathrm{~h}$, which is in agreement with the published materials. The longest recorded persistence time for a sperm-positive internal anal swab (1+) was at a TSI of $85 \mathrm{~h}$ (Fig. 7).

\section{Question 4}

Is there a time interval that you would have an expectation of finding sperm on internal mouth swabs?

TABLE 9-The observed proportion of sperm-positive internal anal swabs with associated $95 \%$ CI at each TSI.

\begin{tabular}{lcccc}
\hline $\begin{array}{l}\text { Time } \\
\text { interval (hrs) }\end{array}$ & $\begin{array}{c}\text { No. of positive } \\
\text { swabs }\end{array}$ & $\begin{array}{c}\text { Total } \\
\text { swabs }\end{array}$ & Proportion & $95 \%$ CI \\
\hline $0-6$ & 27 & 112 & 0.241 & $(0.165,0.331)$ \\
$6-12$ & 21 & 119 & 0.176 & $(0.113,0.257)$ \\
$12-18$ & 8 & 75 & 0.107 & $(0.047,0.199)$ \\
$18-24$ & 8 & 86 & 0.093 & $(0.041,0.175)$ \\
$24-48$ & 8 & 68 & 0.118 & $(0.052,0.219)$ \\
$>48$ & 1 & 42 & 0.024 & $(0.001,0.126)$ \\
\hline
\end{tabular}

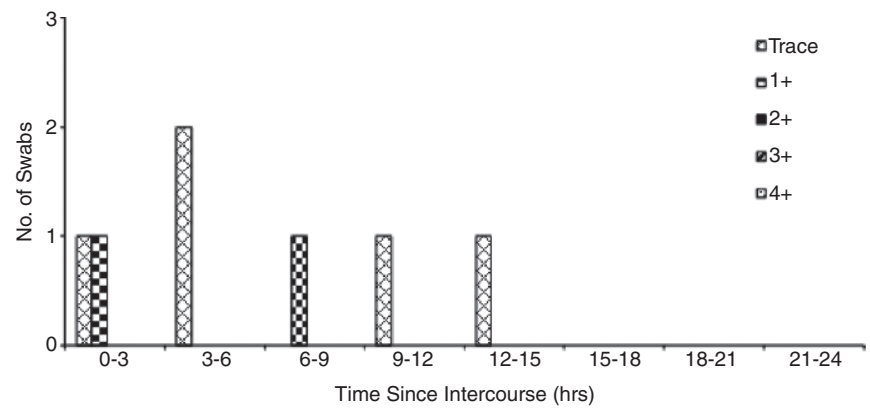

FIG. 8-Persistence and grading of sperm on internal mouth swabs (IMS) at each TSI. Total number of swabs: 405. 
TABLE 10-The percentage of sperm-positive internal mouth swabs at each TSI.

\begin{tabular}{lrrrrrrrrr}
\hline & $0-$ & $3-$ & $6-$ & $9-$ & $12-$ & $15-$ & $18-$ & $21-$ & Total \\
TSI (h) & 3 & 6 & 9 & 12 & 15 & 18 & 21 & 24 & swabs \\
\hline Positive & 2 & 2 & 1 & 1 & 1 & 0 & 0 & 0 & 7 \\
Negative & 45 & 94 & 48 & 60 & 26 & 42 & 34 & 49 & 398 \\
Total & 47 & 96 & 49 & 61 & 27 & 42 & 34 & 49 & 405 \\
$\%$ Positive & 4 & 2 & 2 & 2 & 4 & 0 & 0 & 0 & 2 \\
\hline
\end{tabular}

An additional 24 internal mouth swabs were taken without TSI information supplied; one IMS was positive at trace level. Thirty-five further internal mouth swabs were processed after the 24-h time frame.

Sperm can remain in the oral cavity for up to $6 \mathrm{~h}$ (10). A total of 405 internal mouth swabs were examined; this number includes those samples taken within $6 \mathrm{~h}$ of alleged oral rape using an early evidence sampling kit. Our findings show that the expectation of observing a sperm-positive oral swab is very low (0.02) up to $15 \mathrm{~h}$ TSI. This expectation remains very low for all time intervals (Fig. 8, Table 10). At a TSI greater than $48 \mathrm{~h}$, none of the 13 swabs processed were positive for sperm (data not shown). Our findings suggest that the persistence of sperm in the mouth sampled within $6 \mathrm{~h}$ of the alleged offense is very low but that this very low expectation remains valid up to $15 \mathrm{~h}$. The primary goal of the sexual assault early evidence kits is to rapidly sample sperm in cases of alleged oral rape. A TSI of $6 \mathrm{~h}$ is currently considered an appropriate cutoff time for the use of this kit type. Our findings would suggest that extending the cutoff time up to $15 \mathrm{~h}$ might be more appropriate for the taking of samples of this type. The longest recorded persistence of spermpositive oral swabs was at a TSI of $27 \mathrm{~h}$ (Table 11).

An evaluation of the acid phosphatase reaction as an indicator of sperm on vaginal swabs.

Case assessment and interpretation is an integral part of casework at FSI. The scientist's expectation of whether or not sperm will be present is captured during precase assessment. The forensic scientist may initially consider the TSI between the alleged offense and the medical examination followed by AP reaction time of the swabs. Allard (3) suggests an AP time of less than $65 \mathrm{sec}$ is a fair indication of the presence of sperm (although this must be confirmed by other methods), an AP time of less than $30 \mathrm{sec}$ is a very good indication, and an AP time of $10 \mathrm{sec}$ provides a strong indication for the presence of sperm. The cutoff time of $120 \mathrm{sec}$ is generally accepted as a forensically valid cutoff time for an AP reaction. It should be noted that this AP time point is not a true record of the actual AP reaction time, which may or may not appear at some time after $120 \mathrm{sec}$ in some instances. To investigate whether AP was a reliable measure for the presence or absence of sperm, we examined our

TABLE 11-The observed proportion of sperm-positive internal mouth swabs and associated 95\% CI at each TSI.

\begin{tabular}{llclc}
\hline TSI $(\mathrm{h})$ & No. of positive swabs & Total swabs & Proportion & $95 \% \mathrm{CI}$ \\
\hline $0-6$ & 4 & 141 & 0.028 & $(0.008,0.071)$ \\
$6-12$ & 2 & 110 & 0.018 & $(0.002,0.064)$ \\
$12-18$ & 1 & 63 & 0.016 & $(0.0004,0.085)$ \\
$18-48$ & 1 & 104 & 0.010 & $(0.0002,0.052)$ \\
\hline
\end{tabular}

Eighty-three swabs were taken at a TSI of 18 to $24 \mathrm{~h}$, and none were sperm positive, so this time interval was pooled with a TSI of 18 to $48 \mathrm{~h}$. findings for all vaginal swabs in the database and asked the following questions.

\section{Question 5}

Is AP time a robust indicator for the presence of sperm on vaginal swabs?

Our findings suggest that an AP time of less than $30 \mathrm{sec}$ is a very good indicator of the presence of sperm; for an AP time of less than $30 \mathrm{sec}$, our expectation of observing sperm is very high (between $88 \%$ and $95 \%$ with a confidence interval of $95 \%$ ). There was no significant difference in this expectation for AP times of less than $30 \mathrm{sec}$ and less than $10 \mathrm{sec}$; in our data, both have positive swabs $92 \%$ of the time. Estimates of the proportions of sperm-positive swabs and AP reaction times are given in Table 12.

For AP reaction times of less than $60 \mathrm{sec}$, our expectation of observing sperm is high (0.66), whereas for AP reaction times of greater than $60 \mathrm{sec}$, our expectation of observing sperm is low 0.2 . This would suggest that the forensic scientist should not rely on the predictive value of an AP reaction time greater than $60 \mathrm{sec}$ as an indication of the absence of sperm on vaginal swabs.

To examine this point further, when we examined the 2407 sperm-negative vaginal swabs, a very small proportion, 164 (7\%), had an AP reaction time less than $60 \mathrm{sec}$. Less than $1 \%$ of sperm-negative swabs (19 of 2407) had AP reaction times less than $30 \mathrm{sec}$.

However, of the 1061 sperm-positive vaginal swabs, 560 (53\%) had AP reaction time greater than $60 \mathrm{sec}$ (Table 13). Worryingly, 23\% of sperm-positive swabs (238 of 1061) had a negative AP reaction time (data not shown). At this AP time, we observed the following sperm distributions $40 \%$ at trace level, $34 \%$, at $1+, 16 \%$ at $2+, 5 \%$ at $3+$, and $1.5 \%$ at $4+$.

Our findings suggest that the AP reaction underestimates the expectation of sperm-positive vaginal swabs and supports our previous suggestion that we should not rely on AP reaction times as an indicator of sperm-negative vaginal swabs.

TABLE 12-Proportion of sperm-positive vaginal swabs for each AP reaction time.

\begin{tabular}{lcclc}
\hline $\begin{array}{l}\text { AP time } \\
(\mathrm{sec})\end{array}$ & $\begin{array}{c}\text { No. of sperm- } \\
\text { positive } \\
\text { swabs }\end{array}$ & $\begin{array}{c}\text { Total no. } \\
\text { of swabs }\end{array}$ & $\begin{array}{c}\text { Proportion of } \\
\text { sperm-positive } \\
\text { swabs }\end{array}$ & $\begin{array}{c}95 \% \\
\text { confidence } \\
\text { interval }\end{array}$ \\
\hline $0<\mathrm{AP}<10$ & 36 & 39 & 0.92 & $(0.79,0.98)$ \\
$0<\mathrm{AP}<30$ & 218 & 237 & 0.92 & $(0.88,0.95)$ \\
$0<\mathrm{AP}<60$ & 499 & 665 & 0.66 & $(0.61,0.71)$ \\
$30<\mathrm{AP}<60$ & 283 & 428 & 0.75 & $(0.72,0.78)$ \\
$60<\mathrm{AP}<120$ & 560 & 2803 & 0.2 & $(0.19,0.22)$ \\
\hline
\end{tabular}

TABLE 13-The AP reaction times for sperm-positive and sperm-negative swabs.

\begin{tabular}{llcr}
\hline & AP $<60 \mathrm{sec}$ & AP $>60 \mathrm{sec}$ & Total \\
\hline Positive swabs & 501 & 560 & 1061 \\
Negative swabs & 164 & 2243 & 2407 \\
\hline
\end{tabular}




\section{Question 6}

What if any is the best cutoff time for the AP reaction on swabs?

To answer this question, we examined the true positive (TP) and false positive (FP) rate of AP reaction times for both spermnegative and sperm-positive vaginal swabs. In this setting, a FP result is a sperm-negative swab with a fast AP reaction time (thus indicating a high probability of finding sperm). A TP is a swab that tested positive for sperm and had a fast AP reaction time. The TP rate is a proportion of sperm-positive swabs that had a fast AP reaction and is a measure of sensitivity of the AP test. A good test would have a high TP rate while keeping the FP rate low. We calculated the FP rate and the TP rate for a range of potential cutoff times (Table 14). An informative AP reaction cutoff point would yield a test with a low FP rate and high TP rate.

However, all the AP reaction cutoff times examined from circa 3508 vaginal swabs had a low TP rate showing that as a sensitivity test for the presence of sperm, the AP reaction performs poorly. The TP rate for AP times less than $30 \mathrm{sec}(0.26)$ is equivalent to the $\mathrm{FP}$ rate at an $\mathrm{AP}$ time of less than $90 \mathrm{sec}$ (0.24).

\section{Question 7}

Is there a relationship between AP reaction time and the TSI?

At a TSI of greater than $48 \mathrm{~h}$, no vaginal swabs with an AP time less than $30 \mathrm{sec}$ were observed irrespective of whether or not sperm was present on vaginal swabs (Table 15). The proportion of swabs with an AP time greater than $60 \mathrm{sec}$ steadily increases with the TSI (this increase is statistically significant at the alpha $=0.01$ level). At any given TSI, we observe a range of AP times (figure not presented). If we further examine

TABLE 14-The false positive (FP) rate and the true positive (TP) rate for potential cutoff times for the acid phosphatase reaction.

\begin{tabular}{lcc}
\hline AP reaction time $(\mathrm{sec})$ & False positive rate & True positive rate \\
\hline$<10$ & 0.00 & 0.05 \\
$<30$ & 0.01 & 0.26 \\
$<50$ & 0.06 & 0.44 \\
$<70$ & 0.13 & 0.59 \\
$<90$ & 0.24 & 0.70 \\
$<120$ & 0.32 & 0.78 \\
\hline
\end{tabular}

sperm-positive vaginal swabs with an AP of less than $60 \mathrm{sec}$, we can see that the proportion of these swabs remains similar throughout the TSI intervals (Table 15 and Fig. 9). As can be seen, our findings show that one cannot predict accurately the AP time of swabs given time since intercourse information.

\section{Question 8}

Is there a relationship between time interval and AP reaction time when vaginal swabs are positive or negative for sperm?

We separated our findings into sperm-positive or sperm-negative vaginal swabs and asked this question again. Our analysis showed that there was no obvious clear pattern of relationship other than approximately $90 \%$ of sperm-negative swabs, regardless of the time since intercourse had AP times of $60 \mathrm{sec}$ or greater. We also noted that approximately $50 \%$ of the spermpositive swabs, regardless of time since intercourse, had AP times of $60 \mathrm{sec}$ or greater (Table 16). One would logically

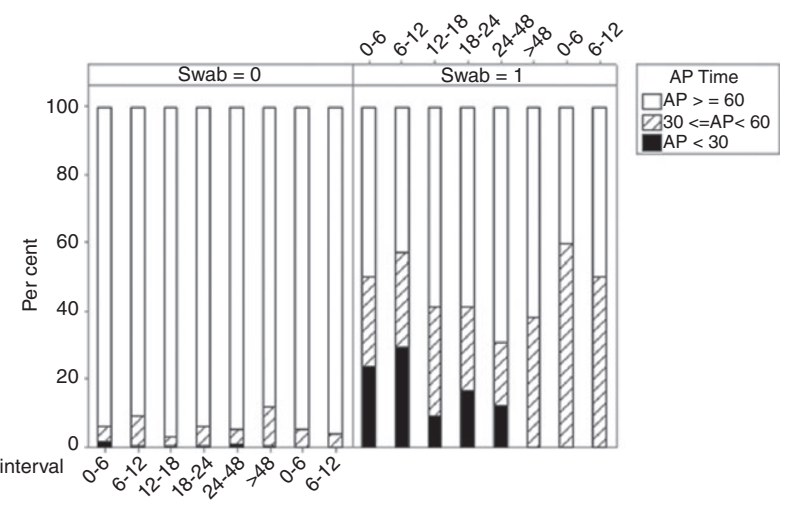

FIG. 9-Proportion of AP reaction times for sperm-positive swabs (positive $=1$ ) and sperm-negative swabs (negative $=0$ ) grouped by AP reaction times $(G p .1>=60 \mathrm{sec}, G p .2=30-60$ secs, Gp. $<=30)$ at each TSI.

TABLE 16-The proportion of sperm-positive swabs with an AP $<60$ and their $95 \%$ CI.

\begin{tabular}{lcc}
\hline TSI $(\mathrm{h})$ & $\begin{array}{c}\text { Proportion } \\
\text { of AP }<60 \text { (positive swabs only) }\end{array}$ & $\begin{array}{c}95 \% \text { confidence } \\
\text { interval }\end{array}$ \\
\hline $0-6$ & 0.5 & $(0.45,0.55)$ \\
$0-12$ & 0.57 & $(0.51,0.63)$ \\
$6-12$ & 0.41 & $(0.34,0.49)$ \\
$18-24$ & 0.41 & $(0.33,0.50)$ \\
$24-48$ & 0.31 & $(0.23,0.40)$ \\
$48+$ & 0.45 & $(0.23,0.68)$ \\
\hline
\end{tabular}

TABLE 15-Percentage of vaginal swabs in each AP grouping (1-3).

\begin{tabular}{|c|c|c|c|c|c|c|c|c|c|}
\hline \multirow[b]{2}{*}{ AP time (sec) } & \multicolumn{9}{|c|}{ Time interval } \\
\hline & $0-6$ & $6-12$ & $12-18$ & $18-24$ & $24-48$ & $48-72$ & $72-96$ & $96+$ & Total \\
\hline $0<\mathrm{AP}<30$ & $10 \%$ & $11 \%$ & $3 \%$ & $4 \%$ & $4 \%$ & $0 \%$ & $0 \%$ & $0 \%$ & $7 \%$ \\
\hline $30<\mathrm{AP}<60$ & $13 \%$ & $15 \%$ & $13 \%$ & $11 \%$ & $8 \%$ & $13 \%$ & $9 \%$ & $6 \%$ & $12 \%$ \\
\hline $60<\mathrm{AP}<120$ & $77 \%$ & $74 \%$ & $83 \%$ & $85 \%$ & $88 \%$ & $87 \%$ & $91 \%$ & $94 \%$ & $81 \%$ \\
\hline
\end{tabular}

Note. Assuming we do not know whether the vaginal swabs are positive or negative for sperm. 
expect that as TSI decreases, the expectation of obtaining a fast AP reaction time increases and the expectation of obtaining a swab positive for sperm also increases. Our findings would suggest that this is not the case. An AP reaction time of less than $30 \mathrm{sec}$ is only seen in time intervals that are less than $48 \mathrm{~h}$ for both positive and negative sperm swabs (Fig. 9).

\section{Conclusions}

The expectation of finding sperm in sexual assault cases is often a critical question asked by the courts not only in Ireland but also in other jurisdictions. Analysis of casework samples in FSI is governed by the case assessment and interpretation model as described by Evett (11) and Gringras (12) and more recently described as "evaluative expert opinion." This study provides guidelines that can assist forensic scientists and medical examiners when considering the expectation of the presence or absence of sperm in sexual assault cases. The findings presented here allow the forensic scientist to formulate robust precase expectations and allow the formulation of probabilistic opinions when asked to provide an expert evaluation in court. The presentation of such opinion evidence has historically been informed by small-published data sets, in house data sets or casework experiences. At FSI, results from the examination of over 5000 intimate swabs, consisting of over 3000 vaginal swabs collected over 7 years, have allowed for the commonly posed questions in sexual assault investigations to be addressed.

The examination for the presence of sperm at FSI on internal vaginal swabs is not carried out beyond a TSI of 7 days. Gingras (12) has shown that the likelihood of obtaining DNA evidence from vaginal swabs remains good for up to a TSI of 3 days. Some States/Jurisdictions do not examine vaginal swabs beyond $72 \mathrm{~h}$. Our data would suggest that this is not best practice; of the 131 vaginal swabs in the SAD at a TSI of greater than $72 \mathrm{~h}, 6$ or $5 \%$ were sperm positive. At a TSI cutoff time for examination of $72 \mathrm{~h}$, valuable forensic evidence may be missed. Moreover, the recent developments of Y-STR profiling chemistries have greatly improved the expectation of obtaining a DNA profile from sperm at TSI greater than $72 \mathrm{~h}$ (13-17).

Our analysis and findings are based on the tip method of sperm extraction from swabs; however, FSI now uses a modified whole swab extraction method (WSE) for the extraction of sperm from intimate swabs. Analysis of the vaginal swabs from 1000 cases processed through our WSE method has shown no significant difference in the observed proportions of sperm-positive or sperm-negative swabs between the two swab processing techniques (data not shown). Our findings show that the expectation of finding sperm beyond $72 \mathrm{~h}$ is extremely low (0.06) and no sperm were detected beyond $120 \mathrm{~h}$ for both the tip or WSE techniques at Forensics Science Ireland.

The forensic science community has historically relied on the AP reaction as the best indicator for the presence of sperm. Following a literature search, Lewis (18) reported no scientific basis for the two-minute AP cutoff time, and additionally, both Lewis (18) and Redhead (19) demonstrated that increasing this cutoff time up to 16 min may be required in certain scenarios. Hofft (20) states that the AP test does not provide reliable information as to the presence of seminal fluid and it is very tenuously related to the number of sperm heads.

Our findings suggests that an AP greater than $30 \mathrm{sec}$ is not a reliable test for the absence of sperm on swabs, although an AP of less than 30 gives a high expectation of finding sperm. These findings call into question the scientific requirement for the processing of vaginal swabs or their supernatants for the purposes of measuring the AP reaction time. Sensabaugh (21) demonstrated very nicely the considerable variation in AP levels through TSI intervals to the extent that there was not enough statistical difference between endogenous AP and postcoital AP levels to allow an assignment of AP values to a particular TSI interval. In the context of DNA profiling, Gringras et al. described the predicative value of AP as poor and showed that $15 \%$ of vaginal swabs and $8 \%$ of anal swabs were negative for the AP reaction provided good-quality DNA profiles. Our findings also question the use of AP reaction times as part of a precase assessment strategy in casework. The use of AP reaction time to inform one's expectations of the presence or absence of sperm on swabs, to estimate the time since intercourse or as a prescreening requirement prior to use of human seminal fluid detection kits such as the "RSID semen kit" or kits for the detection of PSA (P30) on intimate swabs, is unsafe and unreliable. Indeed the use of these kits is a safer approach as they are compatible with DNA profiling chemistries. Allard (22) has suggested that the expert expresses an opinion about the significance of an AP result. Our analysis has very clearly demonstrated the dangers of relying on the AP reaction time on vaginal swabs and that such an approach could be misleading to the courts. We would further suggest that AP testing be left primarily for the testing of textiles, etc. and not intimate swabs. Our results on the persistence and the distribution of sperm from casework samples are in line with most of the previously published works (7-10,23-27). It supports our experiences at FSI in that it is unlikely that sperm will be detected beyond a TSI of $72 \mathrm{~h}$ on vaginal swabs. Our analysis supports the suggestions of Dziak (28) that more emphasis be put on the case TSI data in conjunction with the case background information in formulating one's expectations and forensic approaches to the investigation into sexual assaults.

Our findings and analysis of TSI and the presence of sperm on vaginal swabs suggest the following guidelines; at a TSI of up to $48 \mathrm{~h}$, the expectation of obtaining sperm on vaginal swabs can be considered high (22-42\% at a $95 \%$ confidence interval), and as such, microscopic examination with autosomal DNA profiling may help address the case issue(s); at a TSI of 48-72 h, the expectation of obtaining sperm on vaginal swabs would be lower $(2-14 \%$ at a $95 \%$ confidence interval); serological testing for seminal fluid components followed by either autosomal or Y-STR DNA profiling may be a more prudent approach. For the vaginal swabs with a TSI greater than $72 \mathrm{~h}$, the expectation of finding sperm should be considered extremely low $(0.2-15 \%$ at a $95 \%$ confidence interval) and preserving samples for serological testing for seminal fluid components and Y-STR profiling rather than microscopic examination should be considered.

In cases of alleged oral or anal rape, the expectation of observing sperm-positive swabs was very low even at TSI less than $48 \mathrm{~h}$. After $24 \mathrm{~h}$ TSI in cases of alleged oral rape and $72 \mathrm{~h}$ TSI in cases of alleged anal rape, our findings would suggest that preserving the samples for serological testing for seminal fluid components and Y-STR profiling rather than microscopic examination and autosomal DNA profiling should be considered. In the absence of sperm, penetration without ejaculation should always be considered a possibility. As such, the absence of sperm on intimate swabs does not help address the activity of whether penetration occurred.

The large data set presented here provides greater precision in assigning probabilistic expectations during precase assessment, 
deciding prudent forensic approaches to sexual assault examinations and consequently greater confidence for the presentation of evaluative expert opinion to the courts.

\section{References}

1. Clarke MDB. Metropolitan Police Laboratory examination kit for sexual offences. Police Surgeon 1979;15:47-52.

2. Kind SS. The acid phosphatase test. In: Curry A, editor. Methods of forensic science. London, U.K.: Interscience, 1964;267-88.

3. Allard JE. The collection of data from findings in cases of sexual assault and the significance of spermatozoa on vaginal, anal and oral swabs. Sci Justice 1997;37(2):99-108.

4. Lee-Gorman M, MacNeill S, Rizet D, McDermott SD. Homicide/suspicious death statistics for cases submitted to the forensic science laboratory in the Republic of Ireland for 2004-2008. Med Sci Law 2011;51 (3): $146-50$.

5. Old J, Schweers BA, Boonlayangoor PW, Fischer B, Miller KWP, Reich K. Developmental validation of RSIDTM-Semen: a lateral flow immunochromatographic strip test for the forensic detection of human semen. J Forensic Sci 2012;57(2):489-99.

6. Casey DG, Price J. The sensitivity and specificity of the RSID-saliva kit for the detection of human salivary amylase in the Forensic Science Laboratory, Dublin, Ireland. Forensic Sci Int 2010;194(1-3):67-71.

7. Davies A, Wilson E. The persistence of seminal constituents in the human vagina. Forensic Sci 1974;3(1):45-55.

8. Silverman EM, Silverman AG. Persistence of spermatozoa in the lower genital tracts of women. JAMA 1978;240(17):1875-7.

9. ADavies A. Evaluation of results from tests performed on vaginal, anal and oral swabs received in casework. J Forensic Sci Soc 1997;17(2 3):127-33.

10. Willott GM, Allard JE. Spermatozoa - their persistence after sexual intercourse. Forensic Sci Int 1982;19(2):135-54.

11. Evett IW. Bayesian inference and forensic science; problems and perspectives. Statistician 1987;36:99-105.

12. Gringras F, Paquet C, Bazinet M, Granger D, Marcoux-Legailu K, Fiorillo M, et al. Biological and DNA evidence in 1000 sexual assault cases. Forensic Sci Int Genet 2009;2:138-40.

13. Thompson JM, Ewing MM, Frank WE, Pogemiller JJ, Nolde CA, Koehler DJ, et al. Developmental validation of the PowerPlex ${ }^{\circledR}$ Y23 System: a single multiplex Y-STR analysis system for casework and database samples. Forensic Sci Int Genet 2013;7(2):240-50.

14. Hall A, Ballantyne J. Novel Y-STR typing strategies reveal the genetic profile of the semen donor in extended interval post-coital cervicovaginal samples. Forensic Sci Int 2003;136(1-3):58-72.
15. Mayntz-Press KA, Ballantyne J. Performance characteristics of commercial Y-STR multiplex systems. J Forensic Sci 2007;52(5):1025-34.

16. Mayntz-Press KA, Sims LM, Hall A, Ballantyne J. Y-STR profiling in extended interval $(>$ or $=3$ days) postcoital cervicovaginal samples. J Forensic Sci 2008;53(2):342-8.

17. Hanson E, Ballantyne J. A Y-short tandem repeat specific DNA enhancement strategy to aid the analysis of late reported ( $\geq 6$ days) sexual assault cases. Med Sci Law 2014;54(4):209-18.

18. Lewis J, Baird A, McAlister C, Siemieniuk A, Blackmore L, McCabe B, et al. Improved detection of semen by use of direct acid phosphatase testing. Sci Justice 2013;53(4):385-94.

19. Redhead P, Brown MK. The acid phosphatase test two minute cut-off: an insufficient time to detect some semen stains. Sci Justice 2013;53 (2):187-91

20. Hooft PJ, van de Voorde HP. Bayesian evaluation of the modified zinc test and the acid phosphatase spot test for forensic semen investigation. Am J Forensic Med Pathol 1997;18(1):45-9.

21. Sensabaugh GF, Crim D. The quantitative acid phosphatase test. A statistical analysis of endogenous and post coital acid phosphatase level in the vagina. J Forensic Sci 1979;24(2):346-65.

22. Allard JE, Baird A, Davidson G, Jones S, Lewis J, McKenna L, et al. A comparison of methods used in the UK and Ireland for the extraction and detection of semen on swabs and cloth samples. Sci Justice 2007;47 (4):160-7.

23. Sharpe N. The significance of spermatozoa on victims of sexual offences. Canadian Med Assoc J 1963;89:513-4.

24. Enos WF, Beyer JC. Spermatozoa in the anal canal and rectum and in the oral cavity of female rape victims. J Forensic Sci 1978;23(1):231-3.

25. Davies A. Spermatozoa in the anal canal and rectum and in the oral cavity of female rape victims. J Forensic Sci 1979;24(3):541-2.

26. Willot GM, Crosse MA. The detection of spermatozoa in the mouth. J Forensic Sci Soc 1986;2(26):125-8.

27. Wilson EM. A comparison of the persistence of seminal constituents of the human vaginal and cervix. Police Surgeon 1982;22:44-5.

28. Dziak R. Providing evidence based opinions on time since intercourse (TSI) based on body fluid testing results. Canadian Soc Forensic Sci J 2011;2(44):59-69.

Additional information and reprint requests:

David G. Casey, Ph.D.

Department of Justice and Equality

Forensic Science Ireland

Garda Headquarters, Phoenix Park

Dublin 8

Ireland

E-mail: davidgcasey@gmail.com 